of their nervous organisms to stimuli similar to those which have for ages incited their forerunners.

The bot of horses has been hatched from the egg inside the stomach of its host. After some nine months' residence in the intestines, it is passed with the fæces and subsequently becomes the bot-fly. Until it becomes a perfect insect it has never seen the outside of a horse, and yet, as soon as it sees one, it knows exactly where to deposit its eggs in a position from which they can be licked off and swallowed in their turn. The sight and perhaps the smell of the horse is sufficient to inspire the hereditary desire to deposit eggs in a particular spot. If the stimulus and its reaction were insufficient, that particular bot-fly would cease to propagate.

The garden spider, again, hatched from an egg laid the previous autumn, brings an enormous amount of hereditary skill into the vicissitudes of its life. It selects its site, builds its web, adapts it according to the most approved plans to fortuitous circumstances, and distinguishes between harmless flies and dangerous wasps with an innate cunning which is an exact replica of the actions of the last year's brood. The nest of the trapdoor spider, too, is quite as wonderful a production as the nest of any bird.

Caterpillars, when they have reached their full growth, display great skill in selecting appropriate hiding places in which to pass into the chrysalis form, and those which weave cocoons do so in recognised stages. Huber has described one which makes, by a succession of processes, a very complicated hammock for its metamorphosis; and he found that if he took a caterpillar which had completed its hammock up to say the sixth stage of construction, and put it into a hammock completed only to the third stage, the caterpillar did not seem puzzled, but completed the fourth, fifth, and sixth stages of construction. If, however, a caterpillar were taken out of a hammock made up, for instance, to the third stage, and put into one finished up to the ninth stage, so that much of its work was done for it, far from feeling the benefit of this, it was much embarrassed, and forced even to go over the already finished work, starting from the third stage which it had left off at, before it could complete its hammock. In this experiment it would appear that each instinctive action calls other actions in definite order, and unless the proper sequence is maintained the intelligence of the insect is unequal to bridging the gap.

Now let us apply the facts and inferences aforesaid to the nesting of the chaffinch. We have seen how habits acquired during the life-time of the individual impress themseives upon the nervous connections, until, when the accustomed stimulus is applied, they become quite independent of the will. We have seen how certain reflex phenomena which are necessary for the life of the individual have, through congenital connections, become so automatic, that they take place whether the brain is present or not. We have seen how habits of wild animals have, through similar nervous bonds, been handed down to tame descendants long after the said habits were useless and even detrimental. We have noted that ancestral habits may lie in abeyance until some perhaps unexpected stimulus arouses themfor instance, the scraping of chickens when placed upon gravel, or the diving of a water-bird upon sudden fright. We have ascertained that many of these instincts are certainly not due to instruction by older animals, but are purely spontaneous; that in insects these spontaneous actions are often most complicated, and are sometimes not only carried out in definite order, as in the weaving of their cocoons, but cannot be carried out except in that definite order.

The inference I draw is that the nest-building of the chaffinch is due to a succession of reflexes. You remember that when Alice was wandering about in Wonderland, she was continually coming upon medicine-bottles, marked "Drink me," or upon pieces of cake, marked "Eat me." You remember that when Alice obeyed these directions strange things happened. Alice was able to decipher her labels by the result of long and painful study in her nursery. Had they been written in the Cuneiform character, though perhaps perfectly intelligible to another, they would have conveyed nothing to her. The nervous system of the chaffinch has been educated by generations of hereditary experiences, and when the newly-wedded chaffinch pair start upon their housekeeping, they see in their mind's eye, upon some suitable site, a label marked "Build here"; they go through the stages of their architecture much as the caterpillar spins the different stages of its cocoon, each stage suggesting its successor ; and each twig, hair, or feather which they use, bears upon it a label, "Use me next."

\section{THE EDUCATION OF ENGINEERS}

SEVERAL papers on the training of engineers have recently come under our notice, and it seems worth while to bring together some of the expressions of views upon this important subject. It is difficult, if not impossible, to lay down any hard and fast line as to the course to be adopted by a youth who wishes to become a qualified engineer, for the way to follow must depend largely upon the position, age, prepotency and previous training of the aspirant. Assuming, however, that the principles of science have been studied at school, with practice in the physical laboratory, the question is, what is the next step to be taken? The answers to this are many and various, as will be gathered from the following notes from recent papers on the subject.

A paper on the training of electrical engineers, read by Dr. J. T. Nicolson before the Manchester section of the Institution of Electrical Engineers and published in the Journal of the Institution (May I90I, No. 150), with the discussion upon it, contains some noteworthy statements. The province of the laboratory in the scheme of electrical engineering is, Dr. Nicolson remarks, first to extend scientific knowledge by providing more experimental data; secondly, to show the student the scope, value and limitations of the theories he has studied in the classroom ; and thirdly, to provide object-lessons on the general trend of electrical engineering design by means of machines and instruments of the newest types procurable.

Theory must not, however, be neglected. " Resting on a strong foundation of mathematics, physics and chemistry, the knowledge of the engineer must always include such pure sciences as those of kinematics, dynamics, hydrodynamics, thermodynamics and electrodynamics. A sound elementary acquaintance with all of these is necessary, and a specialised knowledge of that one more particularly useful to the engineer in his own branch must be obtained. It is, for instance, quite hopeless to try to explain to a man who has no knowledge of dynamics, upon what principles one proceeds in endeavouring to balance a locomotive. No amount of laboratory experiment will enable him to dispense with a knowledge of the mechanical principles involved. Again, the fundamental principles of thermodynamics may not be of much use in helping a man to fix the size of the cylinders of a steam engine; but they will, at all events, keep him from wasting his time in trying to design a perpetual. motion machine, and they will show him how far he can hope to go in the direction of the improvement of his heat notors, or other energy transformers." As Prof. Perry has said :- "An electrical engineer must have such a good mental grasp of the general scientific principles underlying his work that he is able to improve existing things and ways of using these things."

This latter qualification, a knowledge of theory, he must acquire by private study and from his college lectures; the former will be best inculcated by experimental work in the laboratory. In the electrical profession, considerable difference of opinion exists concerning the stage at which a youth should enter the works, if he is free to choose. Dr. Nicolson holds strongly the opinion that, after leaving school, the boy who intends to become an electrical engineer should first spend at least two years in the workshops of a mechanical engineer. Here he will learn the elements of smithing, moulding, patternmaking, fitting, machine-work and erecting. In this time he cannot help picking up the names and appearance of the com. mon implements and processes fundamental to all kinds of engineering practice. Having put in two years in a mechanical engineering workshop, Dr. Nicolson thinks the student ought to enter an engineering college at about the age of eighteen, and he ought to study there for not less than three years.

"This last portion of his laboratory time should be devoted by our embryo electrical engineer to what is, in America, called 'thesis' work. This is of the nature of an experimental research, carried out either by the student himself or by a small group of students of which he is one. Very much valuable information has been obtained in American colleges in this way, regarding the various types of new apparatus continually coming out ; and it is found that the students learn, in the course of such work, to assume responsibility by being in a large measure left to their resources. Such investigation usually requires either special apparatus or the loan of new types of machinery ; but good work may also be got by making progressive tests of an operating plant either in the college or elsewhere."

In the discussion upon Dr. Nicolson's paper, the view that

$$
\text { NO. I662, VOL. 64] }
$$


an interval between school and college should be passed in an engineering works was not generally accepted. In the opinion of most speakers, it is better for a youth to go straight from school to a technical college for three years, and to obtain workshop experience after the college training, than to enter works at once. Dr. E. Hopkinson pointed out that for a boy to leave school at about the age of sixteen, and to enter a workshop with the idea of returning to school or college after an interval of two or three years involves a break in the scholastic course, and in habits of learning, which often has disastrous results. The best men are usually those who have had a continuous school and college career up to twenty-two or twenty-three years of age.

Another plan proposed is a combination of the half factory and half technical school, and this system is now under the consideration of the Manchester Association of Engineers. Mr. M. P. Higgins advocates the establishment of schools of this kind in an article in the August number of Feilden's Magazine. Such a school should, he says, possess the following features:- (I) a first-class commercially successful and productive machine. shop, which is a department coordinate in importance, influence and educational value with the academic department ; $(2)$ the pupils to be given instruction and practice in this shop during half the working hours in five days of each week, for a period ot four years; (3) instruction in the public schools to be given during a portion of the other half of the time, equivalent to a high-school course, restricted, abridged and improved to meet the needs of these pupils ; (4) special care and method of selection of pupils who have finished the grammar-school course and who have special aptitude for mechanical work ; $(5)$ management under a corporation whose trustees shall be practical business men.

If technical colleges were equipped with ordinary commercial apparatus and machines and kept in complete touch with engineering advances, much of the difficulty as to training would be removed, fi $r$ students at such colleges would be able to combine the realities of the workshop with the theoretical instruction. But, as Dr. Nicolson pointed out in his paper, the data available in an engineering school are seldom of the latest, unless the teacher spends his summer in obtaining them. The instructor in electrical engineering has the special difficulty of the newness and constant development of his subject to contend with ; but if he follows the practice of every year visiting the plants of the manufacturing companies and typical light and power stations, information is obtained which cannot be found in engineering literature and which has the highest value for educational purposes. The cultivation of close relations between the college and the practising profession should, indeed, be part of the duty of instructors and ought to be eagerly reciprocated by the working engineers as one of the surest ways of meeting foreign competition.

The closer sympathy between science and industry is, indeed, probably the most important factor to be considered. Engineers should see that technical colleges are brought into contact with current work, and arrangements might be made whereby young men from works could be sent from works to the laboratories of scientific institutions to carry on researches for the benefit of the firms employing them. This system is already partly in vogue in Germany and America, and has produced very gratifying results.

This summary of opinion may appropriately be concluded with some extracts from an article on the engineer of the twentieth century, by Prof. V. C. Alderson, Dean of the Armour Institute of Technology, Chicago.

"In the realm of mathematics the training of the engineer will be most rigid and exact. He will cut loose from the idealistic, academic mathematics, as the student of higher literature will cut loose from mere grammars. His mathematics must run down through his fingers, as it were. Mere juggling with symbols will be useless to him. He must regard his mathematics as one of his tools, as a means to an end, or as a language in which to express his thoughts. The future engineer may be successful if his training has included a greater or less amount of shop practice with perhaps indifferent laboratory instruction and a meagre equipment, but no engineer can be broadly successful and thorougbly competent without a deep and exhaustive theoretical treatment of engineering subjects. This does away with the common opinion that literature and books are not essential to the engineer's success, for the next quarter of a century will see the engineering profession rise to the dignity of the older professions.

$$
\text { NO. I } 662 \text {, vOL. } 64]
$$

"The conditions which will beset the engineer of the twentieth century will be exacting beyond anything we now know. The importance of a strong foundation in scientific principles cannot be over-estimated, for scientific principles are only the laws of nature. These principles cannot be learned readily after a man has begun his life work. His whole energy will then be devoted to applying these principles correctly, not in acquiring them laboriously. It will be a prime necessity for the technical college of the future to lay these foundations broad and deep. It will be regarded as a weakness for a college to teach its students only the knacks of the profession, only just enough to be an ordinary draughtsman, a tolerable surveyor, or first-class linesman.

"The technical graduate of the twentieth century will be marked by certain characteristics which are too rarely found in men trained in the colleges of literature and arts. Among these are directness of purpose, intellectual accuracy and clear thinking. The student of science and technology is trained in the realm of realities, where to commit error, to act without purpose, or to think vaguely are seen at once to be fruitful of harm. Economic and industrial needs will bring education from the cloistered lecture-room into the open air of the laboratory. Technical education will have a practical, helpful bearing upon the problems of life. No longer will the seclusion of the scholar be a mark of honour. Education will be found at the bench, by the forge, in the shop, the laboratory and the drafting-room, as well as in the library. The lesson to be taught will be how to apply scientific ideas to the solution of problems actually arising in the struggle to bring the forces of nature under the sway of man.

"As technical education develops, questions of far-reaching importance must be settled. Probably the most important will be the decision as to what kind of man shall guide the technical college. In law, medical and theological schools, the lawyer, the doctor and the minister, respectively, hold first place and have much to say both in the actual training and in the management of the schools. Prominent members of the profession direct the destinies of the schools. To a much less extent do practising engineers influence the technical schools.

"The engineering college represents that form of scientific education most suitable to the exacting demands of advancing civilisation. The particular form of education which it gives through shop and laboratory practice, through practical tests, through acquaintance with the needs of industry, must not and will not be retarded by the classic heirlooms of the literary college. The engineering college must fill its own niche and work out its own salvation. Technical education is an educational and not an engineering problem.

"The technical college in which the future engineer is to be trained has several important characteristics to maintain. First, to educate scientifically and technically those who shall lead the march of the coming civilisation in industrial lines; second, to educate the public to a true sense of the value of applying scientific principles to industrial processes; third, as the university has for one of its functions the extension of human knowledge in any and all lines, so the technical colleges will recognise that the investigation of questions relating to applied science is within its own sphere of usefulness. Probably no investigation to-day would be more fruitful of good results to the engineering profession and to the public at large than the systematic study and thorough test of materials of construction. Such an investigation done on a large scale, on specimens of full building size, in a scientific manner, would save millions of dollars and put the science of construction on a scientific and economic basis. While the university asks no questions about the usefulness of the information gathered within its walls, the technical college must make its investigations in fields that are distinctly useful."

\section{UNIVERSITY AND EDUCATIONAL INTELLIGENCE.}

LORD AVkBURy referred to the neglect of scientific education in secondary schools, in an address delivered at Nottingham on Tuesday, before the Association of Chambers of Commerce of the United Kingdom. He pointed out that the public schools are legally bound, by the regulations made by Lord Salisbury's Royal Commission, to give in all examinations oneeighth of the marks for mathematics, one-eighth for modern languages, and one-eighth for science. How science fares may 